
\title{
25 Research Sourere \\ A Comparative Study of Online Education and Traditional Offline Education During COVID-19
}

Yun Hong

Sun Yat-Sen University Guanghua School of Stomatology

Xiaolan Li

Sun Yat-Sen University Guanghua School of Stomatology

\section{Yingwen Lin}

Sun Yat-Sen University Guanghua School of Stomatology

Jun Xie

Sun Yat-Sen University Guanghua School of Stomatology

Xutong Yan

Sun Yat-Sen University Guanghua School of Stomatology https://orcid.org/0000-0002-1983-2216

Zhengmei Lin ( $\nabla$ Izmlinda@163.com )

Sun Yat-Sen University Guanghua School of Stomatology

Research article

Keywords: COVID-19, Stomatology, education reform, online

Posted Date: September 10th, 2020

DOI: https://doi.org/10.21203/rs.3.rs-61593/v1

License: (c) (i) This work is licensed under a Creative Commons Attribution 4.0 International License.

Read Full License 


\section{Abstract}

Background: In early 2020, a global pandemic (COVID-19) broke out and severely affected the progress of education in various countries' universities and institutions, which promoted the progress of online courses at the same time. This article aims to conduct a comparative analysis of teacher-student surveys between online live teaching and traditional off-line teaching, and explore the direction of medical education reform in colleges and universities.

Methods: Surveys among teachers and students were conducted on live broadcast courses and traditional offline courses by Guanghua School of Stomatology, Sun Yat-sen University, Guangzhou, China. Teachers were investigated from the three aspects including preparation before the class, the experience of teaching during the class, and evaluation after the class, while the students were performed investigations and statistical analysis from the aspects of class experience, learning effect, evaluation of the teachers and curricula.

Results: Both teachers and students fully recognized the orderly organization and management of online live-streaming teaching, and that online courses have a positive and powerful role in improving the quality of teaching. However, teachers and students agree that the overall teaching experience and learning effect of online courses are inferior to offline, so the traditional offline courses or the mixation of online and offline modes are tended for teaching.

Conclusions: The effective and proper use of online education in stomatology can help improve teaching effect significantly, but it is impossible to replace the traditional classroom. In the future, with the addition of online teaching, stomatological education could adopt a new mode of the combination of online and offline teaching as well as the integration of inside and outside the classroom.

\section{Background}

At the beginning of the New Year in 2020, the coronavirus disease 2019 (COVID-19) outbreak became a global public health incident and has constituted a public health emergency of international concern so $\mathrm{far}^{[1]}$, as a result, the online education has been popularized and developed. The epidemic increased not only the importance and urgency of online education, but also provided an opportunity for an in-depth discussion of online education: For medical colleges and universities, how do teachers and students evaluate online teaching? What are the implications for teaching reform? The present manuscript combines the online course management and teacher-student survey of Guanghua School of Stomatology, Sun Yat-sen University, Guangzhou, China to analyze the comparison of online and offline theoretical teaching, aiming at providing a reference for college educators to carry out teaching reform.

\section{Methods}

Verbal consent was obtained from all participants and the study protocol was approved by the Medical Ethics Committee of Hospital of Stomatology, Sun Yat-sen University (No.AF/SC-09/02.0). 


\section{Teaching Organization Method}

1. Teaching schedule: Whether it is a traditional offline course or an online live course, we arranged the curriculum according to the established training plan and syllabus, with no significant difference in the teaching time, frequency, and hours.

\section{Teaching management:}

2.1 Traditional offline course management: In the past, our school's stomatological major theoretical courses were taught separately in two classes, which students in each grade were divided into. Generally, it is a traditional offline course which takes place in the classroom through face-to-face teaching with PowerPoint and the necessary teaching aids. The college requires each teaching and research section to conduct collective lesson preparation and trial training for new teachers. What's more, the teaching experts are regularly arranged to carry out inspection and feedback the results to the education department, while students can evaluate through the university's teaching assessment system.

2.2 Online live course management: This online live course is taught in one class composed of all the students in the same grade, using the innovative "on-site classroom-style" live broadcast method, creating a sense of presence through various ways: the teacher is in formal attire, back to school, entering the classroom and standing on the platform. In order to ensure the quality of the live broadcast courses, the school formulated the Guanghua School of Stomatology 2020 "starting school without returning to school" undergraduate teaching work plan during epidemic prevention and control, and carried out the "Guanghua Internet Celebrity Teachers" selection activity to inspire teachers; each class was broadcast live in the lecture hall of the college equipped with the professional facility and also must have a teaching assistant resident on the teaching site and teaching platform to supervise students' attendance and learning effect at any time; the school also convened teachers and research officers from each educating department for network collective lesson preparation and trial lectures, model lectures and teaching classes observation. In addition, on-site and/or online supervision is arranged for each class. Supervisors include college leaders, teaching supervisors, teaching management staff, multiple directors of educating department and deans. Other colleagues can also silently enter the online classroom to listen to classes at any time.

\section{Investigation Participants}

A total of 46 teachers participated in the survey in this study, whose years of teaching are from 2 to 37 . The proportions of the senior, middle, and junior titles were $57 \%, 47 \%$, and $6 \%$, respectively. They all had traditional offline teaching experience. A total of 11 kinds of professional courses were taught online lively, and 280 hours of live teaching were completed. There were 238 students participating in the survey from Class of 2016 (ie, the fourth grade) and Class of 2017 (ie, the third grade) of our school. They completed the traditional offline majors of 296 and 84 hours before the live broadcast class, and the discussion class, and participated in 196 and 84 hours of live courses this semester. 


\section{Investigation content}

Both teachers and students were asked to fill out detailed questionnaires in order to analyze feedback from both online and offline courses. Teachers' questionnaires are prepared from the aspects of pre-class preparation, teaching experience in class, evaluation after class and comparison of offline courses and online courses (Table 1), while students' are from class experience, listening effect, teacher evaluation, curriculum evaluation, etc (Table 2).

\section{Data collection and statistical approach}

This study belongs to the fixed design of the paired design. First, it is judged whether it meets the applicable conditions of the paired design $t$ test, that is, whether the difference comes from the normal distribution. By performing a normality test on the difference, it is found that the difference is from the normal population ( $W$ test $P<0.05$ ), and finally the Wilcoxon matched-pairs signed ranks sum test is used for statistical analysis. 
Table 1

Questionnaire for teachers: teaching quality of traditional offline courses and online live courses

This questionnaire mainly investigates the advantages and disadvantages of the current online live courses and traditional offline courses, aiming at the better education effect. Please check the following assessment items and then answer or score truthfully (the higher the evaluation, the higher the score).

Before 1. Enthusiasm of teaching theoretical courses

the class

2. Attention level to the online course of your education department

3. Average preparation time for the two-hour class

4. Which aspect did you focus on when preparing for the lesson?

5. Scrupulousness about the medical records leakage

6. Whether to give materials or courseware the classmates before class for preview and review.

7. Whether to arrange quizzes, questions in class or homework after class

In class 1. Adaption to the classroom environment and teaching methods

2. Lecture performance and passion

3. Operating convenience of classroom facilities and equipment

4. Frequency of teacher and student interaction

5. Convenience level of teacher and student interaction

6. Accuracy of the students' answers to questions in class

7. Diligence level of students in class

8. Convenience level of carrying out the reform of teaching methods

After

1. Satisfaction with the teaching effect

class

2. Grading the same content of this live online class taught in different ways

3. Grading the different teaching method on the cultivation of students' independent learning ability

4. Overall, which teaching method is suitable for this course in your opinion?

5. Please rate the teaching management department

6. What difficulties did you encounter during the "online" live teaching process? Please submit If you have any suggestions for improvement

7. The help you need in the process of preparing lessons, making courseware and class

8. Is there any enlightenment for your course teaching reform with this live teaching experience, and how you hope to reform in the future

9. Other suggestions and opinions 
Page 6/19 
Table 2

Questionnaire for students: teaching quality of traditional offline courses and online live courses

This questionnaire mainly investigates the advantages and disadvantages of the current online live courses and traditional offline courses, aiming at the better education effect. Please check the following assessment items and then answer or score truthfully (the higher the evaluation, the higher the score).

Before the class

1. Enthusiasm in class

2. Comfort and convenience level of class

3. Satisfaction with the acquisition of courseware and other learning materials before class

4. Concentration level on the class

5. Interference of the external environment on the class

6. Clarity of teacher's drawing in the class

7. Clarity of the teacher's material object demonstrating in the class

8. Evaluation of the learning effect of the blackboard writing in the class

9. The enthusiasm to answer questions in the class

10. Whether the questions in class can be fed back to the teacher in a timely and effective manner

11.Promptness of teachers' answer and instruction after class

12. Convenience level of review classroom knowledge/after-school review

13. According to your interests/preferences, score the different learning mode

Effect of learning

1. Evaluation of classroom interaction effect

2. Correctness of self-test questions and classwork

3. Evaluation of after-class review efficiency

4. Whether recording and playback of online course is useful for learning

5. Overall learning effect evaluation

6. the reasons influencing learning effect 


\section{This questionnaire mainly investigates the advantages and disadvantages of the current online live courses and traditional offline courses, aiming at the better education effect. Please check the following assessment items and then answer or score truthfully (the higher the evaluation, the higher the score).}

Evaluation of teachers

1. Whether the reaching content is intensively combined with the syllabus

2. The attention level of the teacher to the course

3. The enrichment of the content prepared by the teacher

4. Whether the teacher speaks clearly and at a moderate pace in class

5. Whether the PowerPoint courseware is clear and beautiful in teaching

6. Whether the teacher gives sufficient information in class

7. Whether the teacher can make students fully understand the key points and difficult points of the course content

8. Whether the teacher can organize, manage and control the class well

9. Whether the teacher pay attention to classroom teaching methods

Aspect of course 1. Which mode do you think is more suitable for the theoretical course this semester

2. What is your favorite course in this live course

Satisfaction level of the educating department's work
1. Satisfaction level with the course schedule

2. Satisfaction level with class guidelines

3. Satisfaction level with effective problem solving

4. Overall satisfaction level with the live teaching of our school

5. What are the difficulties encountered in the course of online live classes?

6. Has the learning experience of this live course inspired you to improve your learning methods? If yes, please describe how you would like to adjust in the future.

7. Other Suggestions and comments

\section{Results}

1. Overall satisfaction with the online courses of teachers and students

Teachers and students spoke highly of the organization and management of this online live-streaming lesson, with a score of 10 out of 10, an average teacher score of 9.8, and an average student score of 9 . (Fig. 1, Fig. 2)

2. Teachers and students' feedback on online and offline courses 
Statistics show that both teachers and educating departments attached great importance to online and offline courses. The vast majority of teachers would study course standards and textbooks, find relevant materials outside the textbooks, conduct course design, write teaching plans, and prepare online live lessons. The number of teachers participating in lectures rehearsal was significantly higher than that of offline courses (Fig. 3). Moreover, it took more time to prepare for online courses: to prepare two-hour courses, for offline courses $30 \%$ teachers needed $6-10$ days and $30 \%$ teachers needed more than 10 days while as for online courses $26 \%$ teachers needed 6-10 days to prepare lessons, and $48 \%$ teachers needed more than 10 days to prepare, showing that teachers are more cautious about live broadcast lessons (Fig. 4). In addition, in order to facilitate students' preview and review, up to $63 \%$ teachers will provide learning materials to students before online live classes, and $28 \%$ teachers will send learning materials to students in both online live classes and offline classes (Fig. 5). Correspondingly (figure not shown), students also believed that the teachers of the "online" live-streaming courses attach more importance to the courses, and they were more satisfied with the learning materials such as courseware obtained before the online courses than the offline ones, and $91.18 \%$ of the students believed that the recording and playback of online live lessons was useful for learning. The enthusiasm of the students in the online live class was the same as the traditional offline class. No matter what kind of teaching method, the teacher's teaching content was both closely integrated with the outline; and also there is no difference between the two courses with the regard to the difficulty to grasp the main points, the enthusiasm of the answer questions in class, and the situation of getting the teacher's answers and guidance in time after class.

However, although teachers had put more effort into online teaching before class, and had also made full use of the convenience of the network to carry out a wide range of inspections and supervision, which had significantly improved the quality of teaching, but from the feedback after class, including teachers' adaptability, expressiveness and passion, students' accuracy in answering questions, convenience level of operating classroom equipment and facilities, teacher-student interaction frequency, and overall satisfaction with the teaching effect (Fig. 6), teachers' evaluation score of online courses was lower than that of traditional offline courses. Of the 46 teachers, 24 believed that the courses taught were more suitable for offline traditional teaching, accounting for $52.1 \%$; 22 believed that the courses taught were more suitable for online and offline mixed teaching mode, accounting for $47.8 \%$; no teachers recognized that the courses taught were more suitable for online live-streaming class. (Fig. 7)

Correspondingly, students believed that online courses were not as good as traditional offline courses in terms of classroom interaction, efficiency of after-class review, access to classroom information, and teacher's organization and control of the classroom, and the overall learning effect of traditional "offline" courses were much better. Moreover, the factors that affect the effect of online courses are mainly concentrated on the teaching materials and environment (Fig. 8 and Fig. 9). Therefore, like teachers, they were more inclined to choose traditional offline courses or online and offline mixed modes for teaching.

\section{Conclusion}


Teachers and students were very satisfied with the implementation of online live broadcast courses in special periods, and also affirmed the role of online live-streaming courses in improving the quality of teaching. But in general, teachers and students believed that online teaching is an extension of offline classroom teaching. Effective and appropriate use may help improve the teaching effect, but it is impossible to replace traditional classrooms. Teachers were inspired by this live-streaming lesson. They generally believed that online teaching was a form of teaching that was worth promoting. They planned to increase online teaching and use online and offline, in-class and out-of-class teaching modes.

\section{Discussion}

\section{Analysis of Chinese dental professional courses}

The model of professional education of stomatology in China was decided in 1954 when the Ministry of Education and the Ministry of Health jointly held the National Higher Medical Education Conference. It was based on the background of general medicine, firstly "medical students" and then "stomatological students". At present, the curriculum of stomatology majors in Chinese universities basically continues this model. After the third-year undergraduates formally enter the dental professional course, they are faced with three years of "theory-experiment-practice" interlocking learning. According to the college's training program for undergraduates, the three-year theoretical class has 468 hours (15\%), and the followup experiments and internships are up to 652 hours (21\%) and 1920 hours (64\%). And, after the theoretical course ends, the clinical internship begins immediately, and there is no summer vacation to buffer. Therefore, it is necessary to implement perfect online theoretical teaching during the COVID-19. Based on this opportunity, this study analyzes and discusses the online and offline teaching methods of theoretical teaching in stomatology.

\section{Discussion on online education methods}

With the development of online education today, a variety of online learning models have been formed, such as massive online open course (MOOC) and other massive course sharing or trading platforms, which have also attracted the attention of medical educators. Pei and other scholars ${ }^{[1]}$ conducted a metaanalysis of the literature in 2000-2017, systematically reviewed 3700 articles, selected 16 articles that met the research standards, and discussed the degree of knowledge and skills mastered by online and offline learning for medical undergraduates. Compared with offline learning, online learning has advantages in promoting the knowledge and skills of medical undergraduates and is a feasible method. Coincidentally, scholars such as Tang ${ }^{[2]}$ reviewed 45 literature chapters, and also believed that for medical undergraduates, the integration of online courses into medical education has a high degree of acceptance and good learning results.

Early online education generally adopts the recording and broadcasting class model. This one-way video courseware cannot form a complete learning loop. There are problems such as the absence of student attendance, the teacher's self-talk, and the lack of teacher-student interaction. It is difficult to maintain the 
interactions between teachers and students and the attention of the students. Compared with recording and broadcasting, live teaching is more interactive, can create a learning atmosphere, and can solve the problem of mandatory learning to a certain extent ${ }^{[3]}$. The combination of live broadcast technology and online education has a stronger appeal and freshness for the Internet generation, and can more flexibly compensate for the lack of online learning interaction ${ }^{[4]}$. This brings opportunities for the online education industry, and live broadcast education has gradually begun to rise.

It is worth mentioning that some scholars have studied the classification of interactive problem design of teachers online, using the four dimensions of the structure, aggregation, complexity and cognitive level as the problem classification criteria, and 131 interactive problem designs as the research objects, and analyze the effectiveness of the problem from two perspectives of learner participation and goal achievement. It is found that the interactive problem design of teachers online shows the characteristics of simple and low cognitive level, the overall level of teacher problem design effectiveness is not high, the quantity and quality of the interactive interaction of participants are low. This problem is particularly evident in the first live broadcast class ${ }^{[5]}$. The previous research showed that questions at higher-order levels has the potential to guide trainees into progressively complex thinking and decision making ${ }^{[6]}$. Therefore, live broadcast teachers also need to train and improve teaching skills, learn live broadcast teaching strategies, such as effectively embedding problems in the context, promoting task-driven selfregulated learning, group cooperative learning based on peer evaluation, providing suitable learning supports, and promoting thinking expansion through cooperative debate, etc. ${ }^{[7]}$.

3. The significance of online education for medical education

This study found that under the premise of fully conducting online education analysis, teacher-student research and platform inspection, the convenience and openness of the network platform can be used to more effectively supervise and improve teaching quality. But it is not possible to blindly put online education too high. From the survey results of teachers and students, it can be seen that the traditional face-to-face education is irreplaceable for medical courses, which was consistent with a recent study ${ }^{[8]}$. The online live classes in this epidemic have increased the understanding and acceptance of online education by teachers and students, and inspired the teaching reform ideas. More teachers and students have accepted this teaching model of online and offline integration. Reform has played a positive role in promoting. The true knowledge gained in this kind of practice is helpful for teachers to study the basic laws of scientific cognition, and to actively think and explore teaching methods that are more suitable for themselves and their majors, and therefore more enlightening. We believe that the future education model will better meet the needs of teachers and students and create a new era of medical education.

\section{Abbreviations}

M00C: Massive Online Open Course

\section{Declarations}




\section{Ethics approval and consent to participate}

This study was approved by Medical Ethics Committee of Hospital of Stomatology, Sun Yat-sen University (No.AF/SC-09/02.0), and all the teachers and students provided verbal consent to participate in this study which was approved by the ethics committee.

\section{Consent for publication}

Not applicable.

\section{Availability of data and materials}

The datasets used and/or analyzed during this study are available from the corresponding author upon reasonable request.

\section{Competing interests}

The authors declare that they have no competing interests.

\section{Funding}

This work was supported by grants from 2018 Guangdong Province Clinical Teaching Base Teaching Reform Research Project (2018JD021), Guangdong Province Finance High-level Hospital Construction Special fond from the Best Undergraduate Project (174-2-18-XMZC-0001-03-0125/C-01). The funder had no role in study design, data collection and analysis, decision to publish, or preparation of the manuscript.

\section{Authors' contributions}

Y.H., X.L., Y.Lin. and J.X. conceived, designed and implemented the study. Y.H., X.L. and X.Y. wrote and revised the manuscript. Z.Lin. coordinated the entire study and contributed to the project supervision as well as the manuscript revision. All authors read and approved the final manuscript.

\section{Acknowledgements}

We would like to extend our sincere thanks to the students and teachers who voluntarily participated in this study.

\section{References}

1. Pei $\mathrm{L}, \mathrm{Wu} \mathrm{H}$. Does online learning work better than offline learning in undergraduate medical education? A systematic review and meta-analysis. Med Educ Online. 2019;24(1). doi:10.1080/10872981.2019.1666538 
2. Tang B, Coret A, Qureshi A, Barron H, Ayala AP, Law M. Online lectures in undergraduate medical education: Scoping review. J Med Internet Res. 2018. doi:10.2196/mededu.9091

3. Mukhtar K, Javed K, Arooj M, Sethi A. Advantages, Limitations and Recommendations for online learning during COVID-19 pandemic era. Pakistan J Med Sci. 2020;36(COVID19-S4):27-31. doi:10.12669/pjms.36.covid19-s4.2785

4. Kemp N, Grieve R. Face-to-face or face-to-screen? Undergraduates' opinions and test performance in classroom vs. Online learning. Front Psychol. 2014;5(NOV):1-11. doi:10.3389/fpsyg.2014.01278

5. Liu M, Wu F MZ. Research on the Classification and Effectiveness of Instructors' Interactive Questions in Online Courses. Mod Educ Technol. 2019;29(2):94-100.

6. Magas CP, Gruppen LD, Barrett M, Dedhia PH, Sandhu G. Intraoperative questioning to advance higher-order thinking. Am J Surg. 2017. doi:10.1016/j.amjsurg.2016.08.027

7. Lin X LS. Live Broadcast Teaching Strategies for Cultivating Higher-order Thinking Skills. Mod Educ Technol. 2019;29(3):99-105. doi:10.3969/j.issn.1009-8097.2019.03.015

8. Zhang Q, He Y-J, Zhu Y-H, et al. The evaluation of online course of Traditional Chinese Medicine for MBBS international students during the COVID-19 epidemic period. Integr Med Res. 2020;9(3):100449. doi:10.1016/j.imr.2020.100449

\section{Figures}

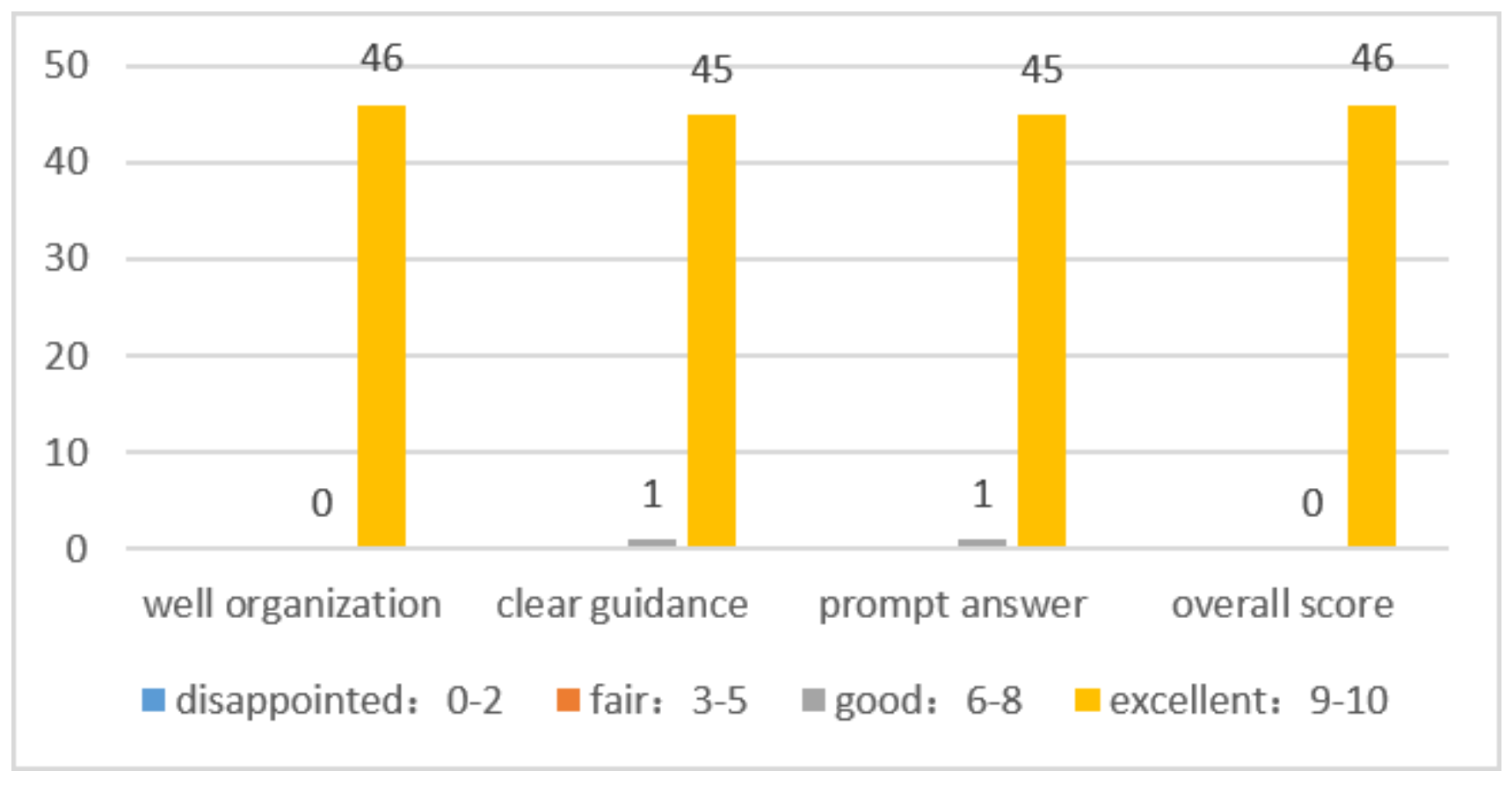

\section{Figure 1}

Survey on teachers' satisfaction. 
\begin{tabular}{ll}
$25.63 \%$ \\
\hline
\end{tabular}

0

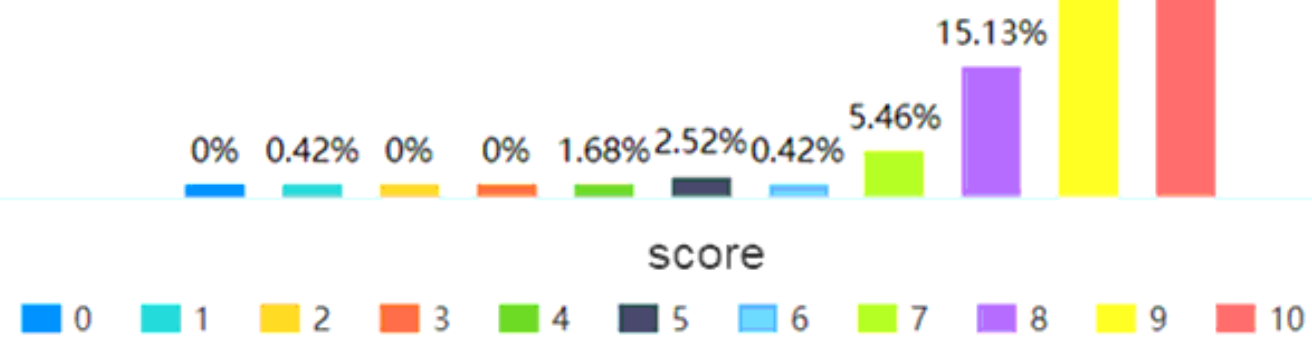

Figure 2

Survey on students' satisfaction.

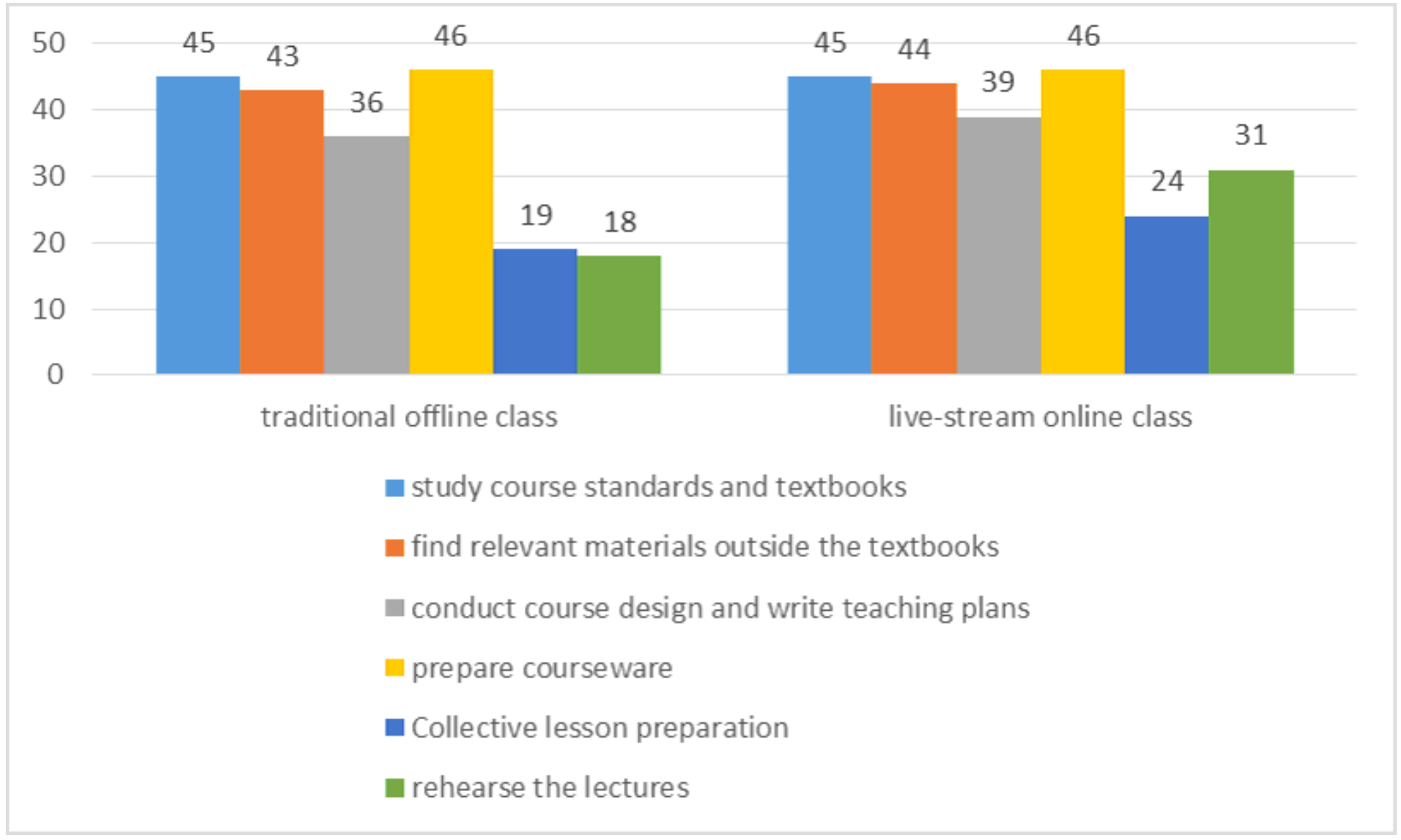

Figure 3

Analysis of online and offline course preparation content. 


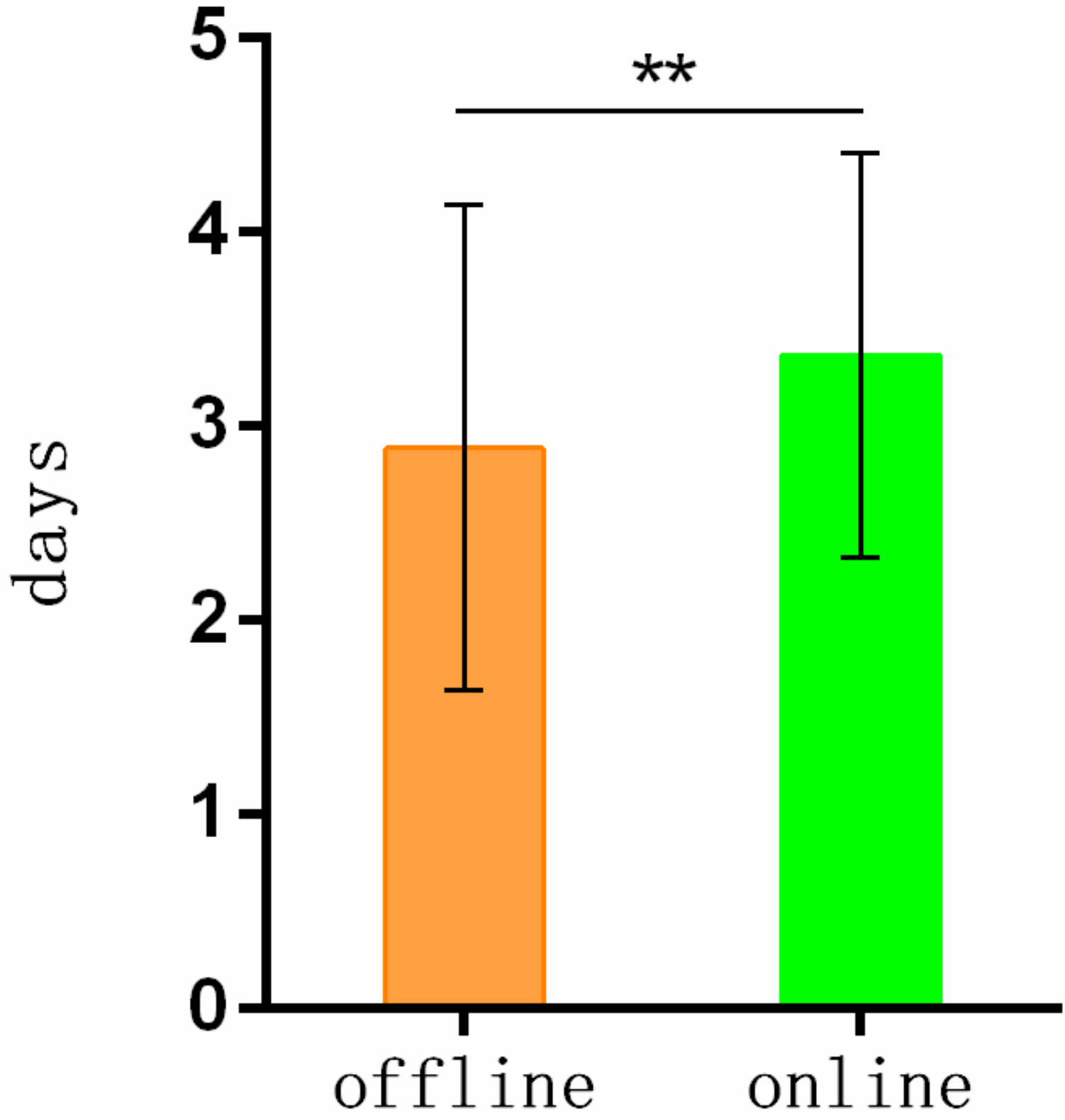

Figure 4

Analysis of online and offline course preparation time. $(* \star p<0.01)$ 


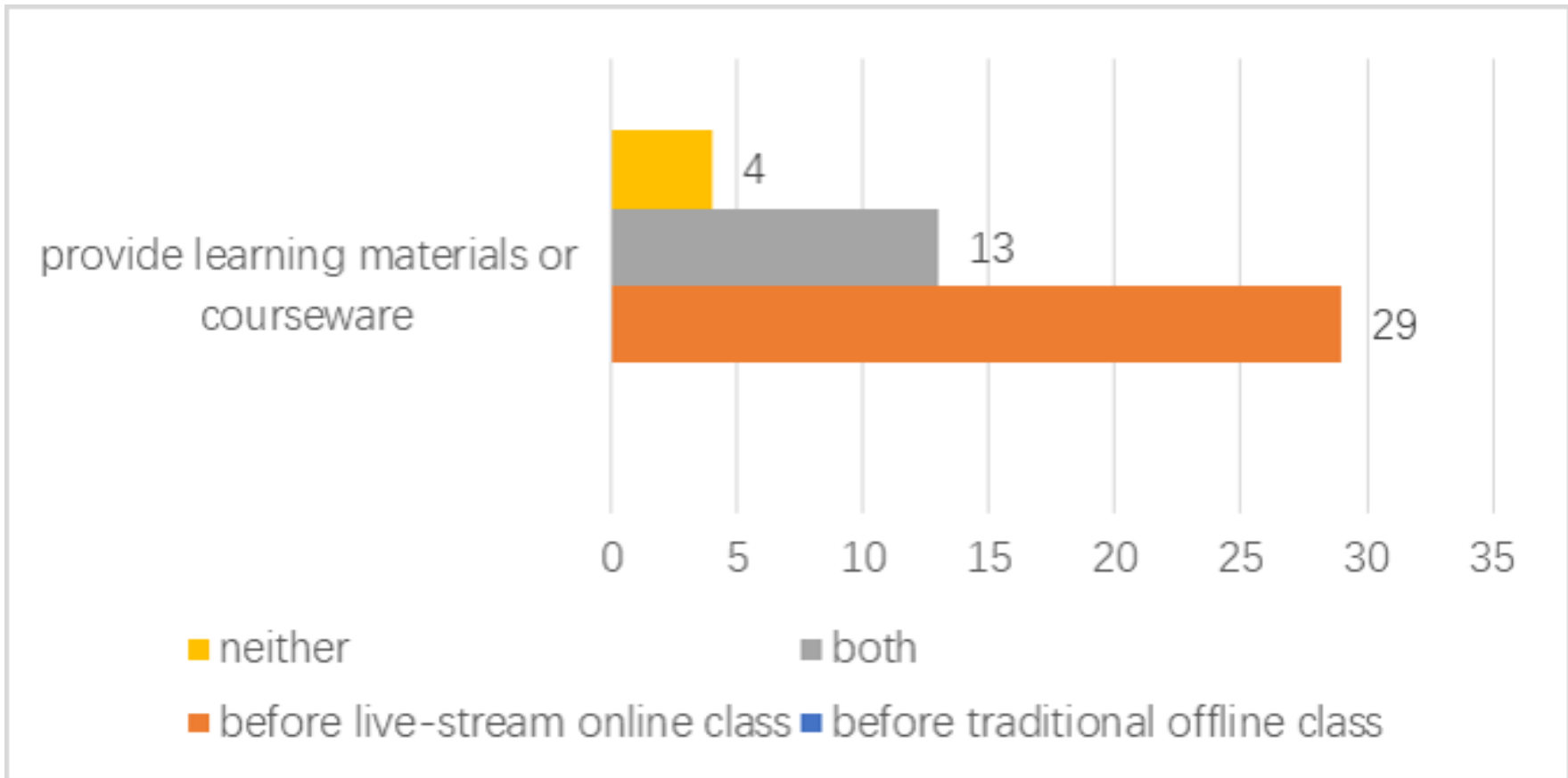

\section{Figure 5}

Learning materials providing condition before class.
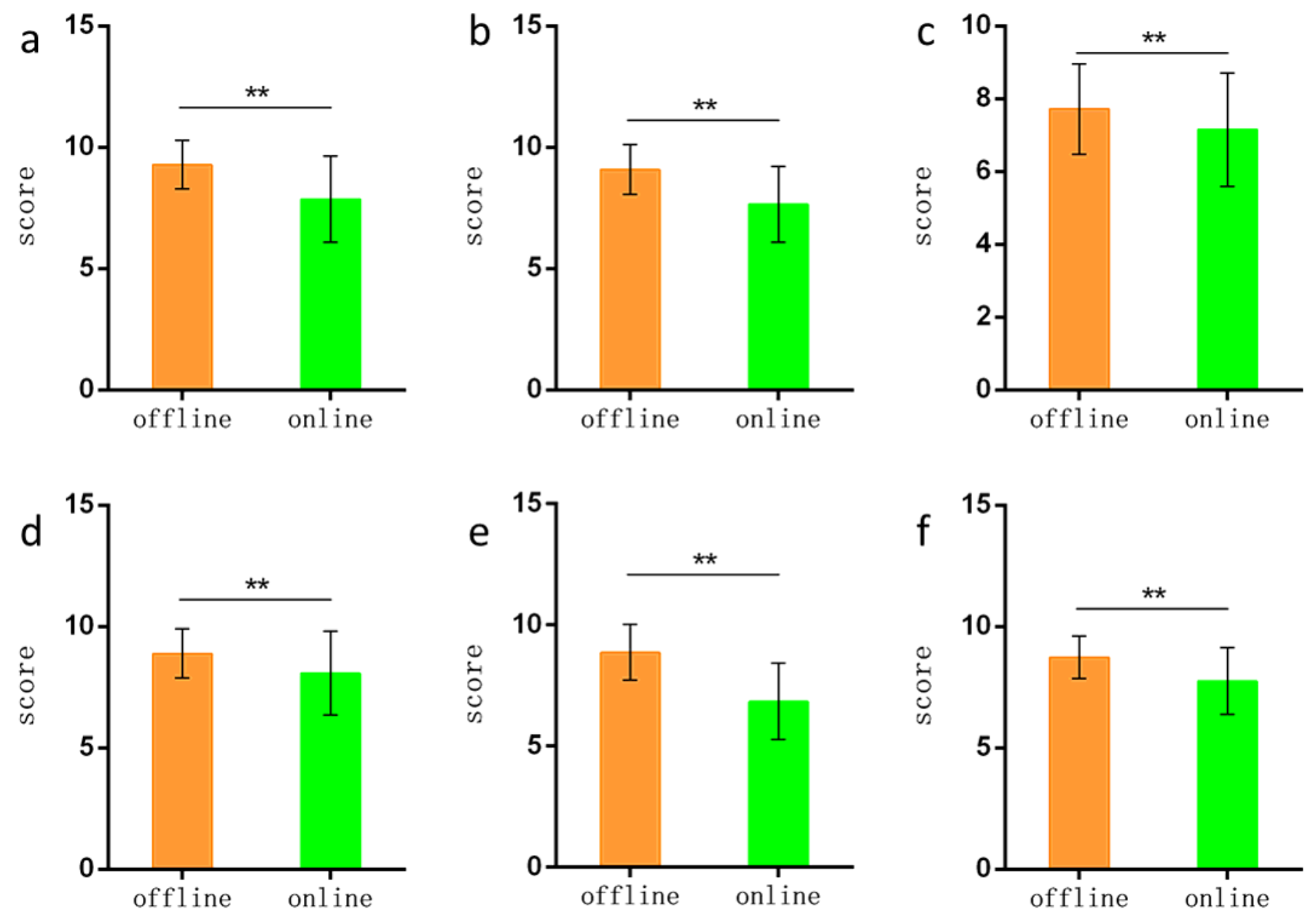
Figure 6

Teachers' evaluation results of online teaching are lower than that of offline one. a, Adaptation to the classroom environment and teaching methods. b, Expressiveness and passion during the lecture. $c$, The accuracy of students answering questions. $d$, Operational convenience of classroom equipment and facilities. e, Teacher-student communication frequency. $f$, Satisfaction with teaching effect. $\left({ }^{\star \star} p<0.01\right)$

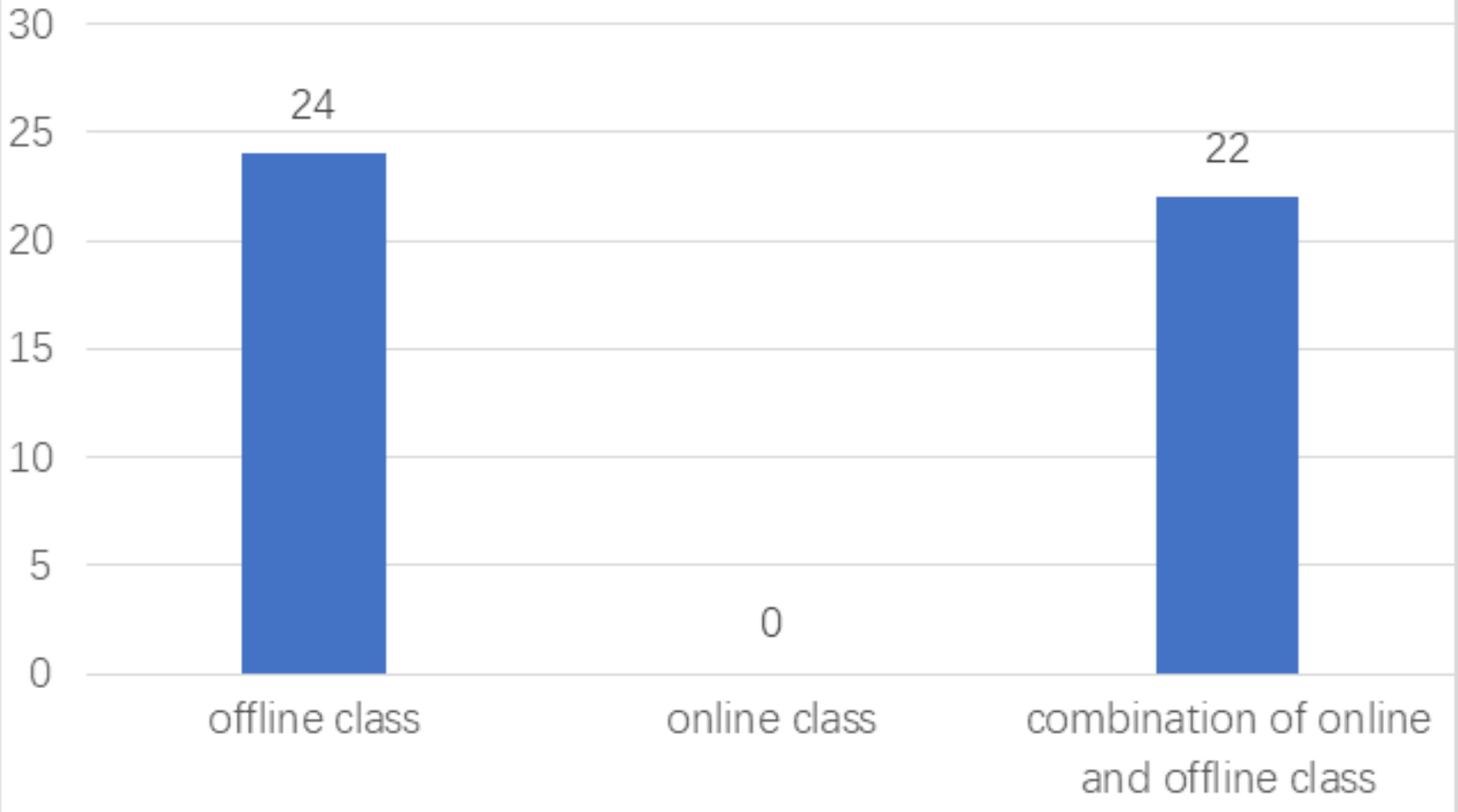

Figure 7

Teachers' evaluation on more suitable method for teaching. 


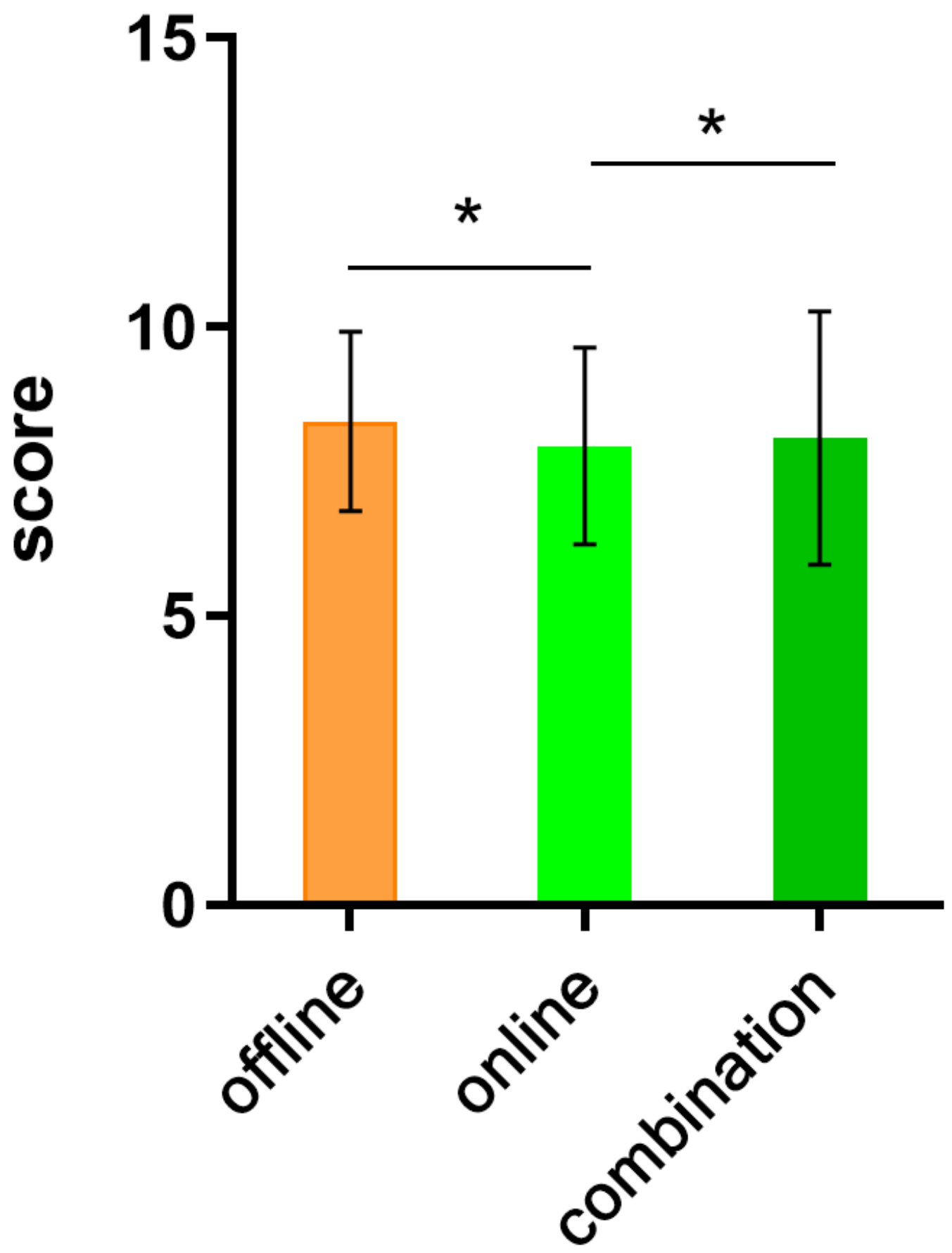

Figure 8

Students' evaluation on different kinds of courses. $\left({ }^{\star} p<0.01\right)$ 


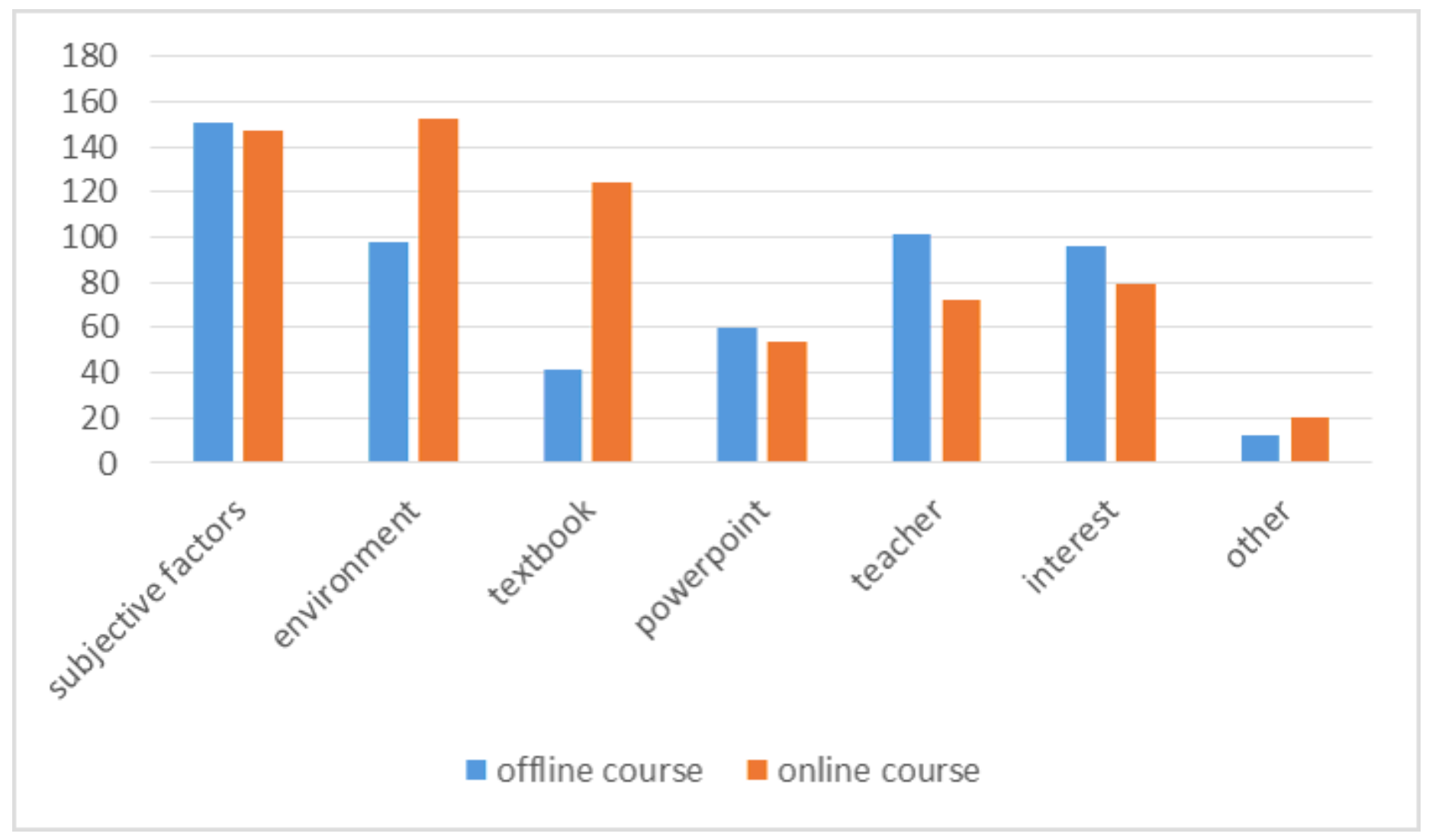

Figure 9

Analysis of the factors influencing learning effect. 